\title{
UN EMPEÑO CIENTÍFICO A GRAN ESCALA:
} LA EUGENESIA

A LARGE-SCALE SCIENTIFIC ENDEAVOR: EUGENICS

UM EMPENHO CIENTÍFICO A GRANDE ESCALA: A EUGENIA

Gilberto A. Gamboa-Bernal' ${ }^{1}$

DOI: $10.5294 /$ pebi.2017.21.1.1

El tema de la edición de genes tiene ahora un nuevo capítulo, gracias a la publicación conjunta de la Academia de Ciencias y la Academia de Medicina de Estados Unidos del informe Human Gene Editing: Science, Ethics and Governance (1). La nueva técnica se muestra como una herramienta poderosa para lograr alterar el material genético de un organismo; en este caso, de los seres humanos. Se explica de qué manera los avances científicos han permitido que cada vez sea más eficiente, más precisa y más flexible, pues incentiva el antiguo interés de mejorar la salud humana.

Sin embargo, dicho interés no se da solo en el ámbito de las ciencias de la salud: también los políticos, algunos medios de comunicación y una pequeña facción de científicos vuelven a manifestar sus inquietudes sobre varios puntos. Algunos de ellos son: el necesario y adecuado control de estas biotecnologías; el grado de información y participación de la sociedad en general, sobre las decisiones que se van tomando; si los beneficios potenciales compensan los riesgos que tienen estas técnicas; si los principios éticos son totalmente respetados en las aplicaciones clínicas; si las decisiones políticas son respetuosas de la diversidad

1 Universidad de La Sabana, Colombia. gilberto.gamboa@unisabana.edu.co cultural de las distintas naciones; la intervención en la línea germinal humana.

En lugar del foro internacional permanente que fue indicado en las conclusiones de la cumbre internacional de finales de 2015 (2) para estudiar el estado actual de la investigación sobre la materia y sus posibles aplicaciones clínicas en los seres humanos, las academias Nacionales de Ciencias, Ingeniería y Medicina de Estados Unidos anunciaron al mundo, el 14 de febrero de 2017 (3), que ya estaba disponible un informe preparado por el Comité sobre la Edición de Genes Humanos: Consideraciones Científicas, Médicas y Éticas. Este comité estuvo conformado por representantes de dieciséis universidades (doce de Estados Unidos, una de Israel, una de Francia, una de Italia y una de Canadá); cuatro institutos de investigación y organizaciones no gubernamentales (una de Estados Unidos, una del Reino Unido, una de China y una de Egipto), y dos industrias, una dedicada a investigar en temas de la vida (Salk Institute for Biological Studies) y una empresa de inversión en ciencias de la vida (Bay City Capital).

Este Comité muestra en su informe las nuevas oportunidades de investigación; así como las actuales y potenciales aplicaciones clínicas para la prevención y curación de varias enfermedades o discapacidades. 
Se insiste en atenerse al marco regulatorio existente para las terapias génicas y en evaluar tanto la seguridad como la eficacia de las aplicaciones somáticas de la nueva técnica. Llama la atención la preocupación que hay en la opinión pública acerca de la posibilidad de utilizar la técnica para modificar rasgos o habilidades humanas (inteligencia, fuerza física, destrezas, etc.) y afirma que, al menos en este momento, no se deben acometer esos derroteros y dejar abierta la posibilidad de que en un futuro sea posible hacerlo.

Se reconoce que, al menos, es polémica la situación de propiciar cambios genéticos que la siguiente generación vaya a heredar; pero se ha dado un avance en este sentido: antes ni se mencionaban las próximas generaciones como personas en quienes también se producirán los efectos de la técnica. Categóricamente se afirma que este tipo de aplicación no está lista para ser probada en seres humanos; pero es solo cuestión de tiempo y de que las técnicas se perfeccionen para que se produzca el siguiente paso. En el informe se sostiene que "hacer la edición en el genoma hereditario de embriones tempranos, óvulos, espermatozoides o células precursoras es previsible en el futuro, es una posibilidad realista de que merece una seria consideración". Se sugiere que este tipo de investigación debe hacerse con precaución; pero para el Comité precaución no es sinónimo de prohibición.

En este sentido, las políticas de varios países, entre ellos Estados Unidos, que han firmado una convención internacional que prohíbe la manipulación y modificación de la línea germinal, no deberían ser permanentes y en más o menos poco tiempo podrían cambiar. Para cuando esto pase, el Comité hace recomendaciones estrictas para ir adelantando terreno antes de empezar los ensayos clínicos, en el momento en que se levanten las restricciones actuales. Los criterios que contiene el documento son:

1. Mostrar que no hay alternativas razonables.

2. Demostrar, de forma convincente, que la restricción a la edición de los genes causa o predispone a una grave situación o condición.

3. Conseguir datos preclínicos o clínicos creíbles sobre los riesgos y los beneficios potenciales para la salud.

4. Diseñar una supervisión rigurosa para los ensayos clínicos.

5. Trazar planes de seguimientos integrales y multigeneracionales para largo plazo.

6. Preparar una nueva evaluación de los beneficios y los riesgos para la salud y la sociedad, con una amplia participación de la población.

7. Establecer mecanismos de control fiables para prevenir la extensión a usos distintos de la nueva biotecnología.

El informe hace hincapié en recomendar que se formulen las políticas para las aplicaciones de la edición de genes contando con la participación ciudadana. También en que el financiamiento de la investigación se debe extender al estudio de los aspectos sociopolíticos, éticos y legales, para facilitar el diseño de la estrategia de comunicación y lograr así el respaldo y la aceptabilidad de la población. Es pertinente recordar que esta forma de proceder, a través de modelos de aceptación pública (4), ya está suficientemente probada, principalmente en los estudios auspiciados por la Organización Mundial de la Salud para el desarrollo de nuevas tecnologías para el control de vectores y la fabricación de vacunas (5). 
Desde una perspectiva bioética, esta forma de actuar tiene algunos cuestionamientos: la aceptabilidad inducida por los planes de "aceptación pública", que en poco o nada se diferencian de las estrategias de mercadeo, no hace que una práctica investigativa sea buena, ni que los riesgos inherentes a ella disminuyan. El hecho de que tal práctica se haya mostrado exitosa tampoco la hace adecuada, pues lo que en el fondo se busca no es solo informar, sino promover un respaldo comunitario, para que no se obstaculice el desarrollo del proyecto por el rechazo natural de la opinión pública a la eugenesia.

Por otro lado, el informe recomienda unos principios generales que "deben ser utilizados por cualquier nación para la reglamentación de la investigación en la edición genoma humano o sus aplicaciones". Estos principios son:

- Promover el bienestar: proporcionar beneficio e impedir el daño a los usuarios.

- Transparencia: apertura e intercambio de información, de manera que sean accesibles y comprensibles para los pacientes, sus familias y grupos de interés.

- Necesario cuidado: proceder solo cuando se disponga de pruebas suficientes y robustas.

- Ciencia responsable: adherirse a los más altos estándares de investigación, de acuerdo con las normas internacionales y profesionales.

- Respeto por las personas: reconocer la dignidad personal de todos los individuos y respetar sus decisiones.

- Equidad: manejar todos los casos por igual, con una distribución equitativa de los riesgos y beneficios.

- Cooperación transnacional: compromiso de colaboración para la investigación y la gobernabilidad en el respeto de los diferentes contextos culturales.
Algunos de estos principios generales son llamativos y aparentemente plausibles, pero merecen comentarios: Están encabezados por una llamada a la promoción del bienestar como si ese fuera el bien más necesario para el mundo. Este planteamiento, que se fraguó a la par con el Plan Marshall, se ha venido extendiendo hasta hacerse una de las características principales del cambio de cultura que el mundo está viviendo: importa más el bien-estar que el bien-ser.

El principio de transparencia no parece suficientemente tenido en cuenta cuando se interactúa con la opinión pública; solo en el sentido de hacerla favorable a los cambios que se pretenden. Sin embargo, esa transparencia no se predica en relación con un amplio debate académico y social, donde los medios de comunicación deben ser imparciales.

Apelar a los altos estándares de investigación solo haciendo referencia a las normas internacionales y profesionales implica desconocer las reglamentaciones nacionales o sectoriales, que en los Estados de derecho deben prevalecer.

Es paradójico que se hable de respeto por las personas cuando en el fondo se están apoyando unos desarrollos biotecnológicos que pueden costarle la vida a muchos seres humanos, incluso desde sus primeras etapas. Pero lo es aún más cuando se afirma que es necesario establecer un "compromiso preventivo que impida la repetición de las formas abusivas de eugenesia practicadas en el pasado", cuando esta nueva biotecnología, precisamente, modifica rasgos o habilidades humanas, lo que equivale a eugenesia, que en ninguna parte del informe está proscrita. En cambio, sí se contempla esa posibilidad para más adelante, tal vez cuando la opinión 
pública tenga una mayor favorabilidad, secundaria a las estrategias de aceptabilidad y de mercadeo que se contemplan para la difusión de la edición de genes.

En ese mismo ítem del respeto por las personas se hace una defensa a la centralidad de la elección personal, donde se absolutiza la libertad y se pone por encima la decisión personal sobre el bien de la misma persona, aunque se reconozca que todas las personas tienen un valor moral, que es independiente de sus cualidades genéticas.

También es llamativo que en el principio de equidad se hable de distribuir equilibradamente no solo los beneficios, sino también los riesgos, invocando la justicia distributiva para hacerlo. Este tipo de justicia hace referencia al derecho que tiene cada ser humano de recibir lo que le corresponde en la relación que mantiene con los demás individuos y con la totalidad social (6). No queda claro que los sujetos tengan derecho a los riesgos que comportan la nueva tecnología, ya que los riesgos no hacen parte del bien común.

Estos principios son difíciles de aplicar en uno de los puntos en los que el informe reconoce que todavía no es tiempo de abordar, pero que más adelante sí se podrá hacer: la edición de la línea germinal del genoma. Para ello se aventura uno de los posibles argumentos:

El acceso a la edición de la línea germinal del genoma sería coherente con las interpretaciones legales y culturales más amplias de los derechos de autonomía de los padres en los Estados Unidos [...]. Impedir el acceso a esta tecnología podría considerarse como una limitación de autonomía de los padres, dependiendo del país y la cultura. De hecho, algunas personas sienten que tienen un mandato religioso o histórico para tener hijos genéticamente relacionados.

Estas afirmaciones han encontrado eco en publicaciones no solo científicas, sino también del mundo económico (7), donde se sostienen argumentos como la necesidad de evitar el sufrimiento de personas "cuyas vidas se ven arruinadas por la falta de hijos o enfermedad genética, que sostienen con pasión el derecho a aliviar el sufrimiento". También se muestra que la edición de genes eliminará las enfermedades genéticas, evitando una de las formas de hacerlo hasta ahora: la selección de embriones, "avance que muchos aplaudirían". Por otro lado, se sostiene que la nueva biotecnología es un progreso positivo a las técnicas de reproducción asistida y de clonación humana, donde la regla para actuar en cualquier tecnología reproductiva es tener "padres felices y niños sanos”.

Sin embargo, otros científicos han manifestado su extrañeza por el aliento que el informe da a esta biotecnología, pues supone un cambio drástico al acuerdo existente y generalizado en el mundo: la edición de la línea germinal humana debe ser prohibida. Así lo sostiene Marcy Darnovsky, directora ejecutiva del Centro de Genética y Sociedad de la Universidad de California (8). En la página web de ese centro se encuentra material interesante y abundante que respalda esa afirmación, como el "Human Gene Editing: A Timeline of CRISPR Cover Stories” (9).

Otro de los temas que es insuficientemente tratado en el informe es el de las patentes. Parecería que se pueden limitar las posibilidades para que esta tecnología sea protegida como propiedad intelectual. También parece factible una protección, pero diseñando sistemas amplios y no exclusivos de licenciamiento que posibiliten 
la difusión de la tecnología, pero esta opción dependerá de quienes suscriban la patente (10).

Este ha sido el campo en el que se produjeron las primeras reacciones luego de la publicación del informe del 14 de febrero de 2017. Una semana después, el 22 de febrero, la Oficina de Patentes y Marcas de Estados Unidos dirimió el litigio entre el investigador chino Feng Zhang, al servicio del Broad Institute, de las universidades de Harvard y MIT, y las doctoras Emmanuelle Charpentier y Jennifer Doudna, del Instituto Max Planck y la Universidad de California, respectivamente. Hace unos años, las dos investigadoras desarrollaron la CRISPR/Ca9, publicación aparecida en Science (11), y procedieron a tramitar la patente; pero solo de la utilización de la herramienta con un tipo de bacterias. Zhang, por su parte, tramitó una patente express, más costosa, para la utilización de la herramienta CRISPR-Cas9 en cualquier entorno, incluyendo las células eucariotas y otros tipos de células. La Oficina de Patentes falló a favor de Zhang, en primera instancia, pues consideró que la patente amplia de Zhang era suficientemente distinta de la patente de la contraparte. Las apelaciones a la decisión con seguridad no se harán esperar, pues la batalla que apenas empieza tiene en el fondo una gran cantidad de dinero (12).

Es innegable que el informe supone un fuerte espaldarazo a la edición genética en seres humanos; pero también es cierto que se trata de un aval demasiado laxo. En el texto se deja abierta la posibilidad de alterar genéticamente tanto óvulos y espermatozoides como embriones, al establecer unas mustias pautas que incluyen trabajar en alteraciones genéticas totalmente demostradas, determinantes de enfermedades graves, cuando no se encuentren otras alternativas razonables y sea factible hacer un seguimiento al proceso durante varias generaciones.

Es interesante conocer de qué manera se financió este Comité. El trabajo del comité autor del informe recibió fondos de tres instituciones gubernamentales de Estados Unidos (la Agencia de Proyectos de Investigación Avanzada de la Defensa, el Departamento de Salud y Servicios Humanos y la Administración de Drogas y Alimentos) y cuatro fundaciones (Greenwall, John D. y Catherine T. MacArthur, Wellcome Trust y Kellogg). El trabajo que estos realizan haría pensar que existen fuertes conflictos de interés. Basta revisar cuáles son los proyectos e investigaciones que apoyan económicamente para darse cuenta de que la inclinación que pueden tener en el desarrollo de esta biotecnología rebasa la simple filantropía o el deseo de contribuir al bien de la sociedad y del futuro del mundo.

Por ejemplo, la Greenwall Foundation, si bien auspicia la formación en bioética de los investigadores para lograr "una comunidad de investigadores innovadores en Bioética y ayudar a resolver los dilemas éticos en la atención al paciente, la investigación biomédica y las políticas públicas", apoya económicamente a organizaciones como la Choice in Dying, que abogan por los derechos de los enfermos terminales y sus familias para la ayuda al suicidio asistido y la eutanasia; invirtió en la publicación del libro The Oregon Death with Dignity Act: A Guidebook for Health Care Providers. Además, han financiado investigación en células madre embrionarias, a pesar de las políticas de la administración del presidente Bush sobre el tema (13).

La John D. y Catherine T. MacArthur Foundation trabaja principalmente en temas de encarcelamiento 
excesivo, del cambio climático global, del riesgo nuclear, en el aumento significativo del capital financiero para el sector social y en el papel del periodismo para conseguir democracias responsables, con el objetivo de "contribuir a lograr un planeta más justo, verde y apacible”. Aparte de lo anterior, tiene una línea de acción en población y salud reproductiva en países como Nigeria, México e India, que sigue el enfoque de los Objetivos de Desarrollo del Milenio, aunque están planeando abandonarla (14). La Wellcome Trust Foundation es, después de la Fundación de Bill y Belinda Gates, la segunda financiadora privada más grande del mundo para la investigación biomédica. Tiene su sede en Londres y un portafolio muy amplio de las áreas de investigación que apoya. Su ideal es "la buena salud hace la vida mejor. Queremos mejorar la salud para todos, ayudando a prosperar grandes ideas" (15). Particular relevancia tiene la inversión en los programas de genómica estructural y el apoyo al Instituto Sanger, uno de los principales sitios de secuenciación del genoma, donde además trabajan activamente con el sistema CRISP /Ca19 (16).

El centro de la actividad de la Fundación Kellogg es el óptimo desarrollo de la infancia, en general, y en situación de vulnerabilidad, en particular. Sin embargo, también apoya programas de "salud sexual y reproductiva" en diversos sitios del planeta (17) e iniciativas e investigaciones (18) donde se promueven los "derechos sexuales y reproductivos” a los jóvenes y las mujeres (19).

Finalmente, lo que hay en el fondo del informe del Comité sobre Edición Genética es un respaldo encubierto a la eugenesia, que propone como pautas éticas solo la seguridad en las investigaciones y que sean respaldadas legalmente. Se debería procurar que el beneficio parcial para la sociedad, en términos de cura de enfermedades, sea real y extenso, sin perjuicio del impacto de la tecnología y su utilización a escala más industrial, con un licenciamiento amplio, barato y genérico. Esto, siempre y cuando la nueva tecnología respete la vida de cada ser humano, incluso desde sus primeras etapas de desarrollo celular.

En este número de Persona y Bioética se dan cita, por primera vez, trabajos escritos en las tres lenguas en las que se presentan los resúmenes: español, inglés y portugués. El artículo en inglés, "Ethical Conducts of Professors, Undergraduate and Postgraduate Students: Dental Schools' Patients View", es de un grupo de investigación brasileño de la Facultad de Odontología de la Universidad Ribeirão Preto, conformado por Letícia Oliveira Tonin, Letícia Ferreira dos Santos, Cristhiane Leão de Queiroz, Julia Gabriela Dietrichkeit Pereira y Ricardo Henrique Alves Silva Correo.

El trabajo en portugués se encuentra en la sección “Jóvenes investigadores", donde el estudiante de derecho Ramiro Ferreira de Freitas escribe sobre "Condicionada a seleção artificial: eliminar os mais fracos ou homogeneizar a 'raça'?". El otro artículo de esta sección, "Cobertura periodística sobre el suicidio: ¿habría riesgo de causar efectos negativos en personas susceptibles?”, lo escriben los estudiantes de Medicina Estefanía Suárez, Julián Barrera, Mariana Gómez, Nicolás Velásquez y Teresa López, asesorados por la psiquiatra Yahira Guzmán y el periodista Víctor García, de la Universidad de La Sabana de Colombia.

De España nos llega el interesante artículo "Naprotecnología: ciencia y persona en la infección por el virus del papiloma humano (VPH) en mujeres y preadolescentes", donde el equipo liderado por José María Murcia Lora 
presenta una propuesta para mejorar la prevención de las infecciones por el VPH.

El artículo "Encontrar sentido para continuar viviendo el reto al perder un hijo por cáncer infantil: revisión integrativa”, escrito por Sonia Patricia Carreño Moreno, Olivia Lorena Chaparro Díaz y Rocío López Rangel, de la Universidad Nacional de Colombia, ofrece un valioso material que ayudará a muchas familias y profesionales de la salud que se encuentran frente a la dura situación de tener un paciente con cáncer infantil.

Desde Chile, Ángela Arenas Massa y Carolina Riveros Ferrada escriben sobre los "Aspectos éticos y jurídicos de la salud ocupacional”, un tema de biojurídica que tiene pocos antecedentes en la literatura y que lo hace, por eso mismo, muy relevante.

Águeda Muñoz del Carpio Toia presenta "Efectividad de la adecuación cultural y capacitación sobre el nivel de comprensión del proceso de consentimiento informado en un proyecto sobre nutrición escolar en un pueblo indígena aymara de Perú”. María Elizabeth de los Ríos Uriarte, de México, escribe el interesante ensayo "La cuestión del método en bioética clínica: aproximación a una metodología adaptada al contexto de la realidad mexicana", donde aborda un tema urgente de profundizar para mejorar el trabajo que se hace en bioética. "Las TIC soporte importante en el desarrollo de los saberes, reflexión desde el contexto bioético”, de Ángela María Wilches Flórez y Olga Cecilia Wilches Flórez, de la Universidad Distrital de Colombia, plantea la utilización de las tecnologías de la información y la comunicación en el área de la salud.

La sección "Bioética en práctica" incluye el aporte de Richard Stith, "La personalidad del embrión: la filosofía ante los límites de la imaginación”, escrito que fue presentado en la X Jornada de la Asociación Española de Personalismo, realizadas en Madrid, en mayo de 2016.

\section{REFERENCIAS}

1. Human Genome Editing. Science, ethics, and governance [internet]; 2017 [Citado 2017 feb 14]. Disponible en: https:// www.nap.edu/catalog/24623/human-genome-editing-scienceethics-and-governance

2. The National Academies of Sciences, Engineering, and Medicine. On human gene editing: International summit statement [internet]. [Citado 2016 mar 19]. Disponible en: http://www8.nationalacademies.org/onpinews/newsitem. aspx?RecordID $=12032015 \mathrm{a}$

3. The National Academies of Science, Engineering and Medicine. News [internet]. [Citado 2016 feb 14]. Disponible en: http://www8.nationalacademies.org/onpinews/newsitem. aspx?RecordID=24623\&_ga $=1.225732890 .1840301603 .1487$ 601842

4. World Health Organization. Global vector response: $2017-$ 2030 [internet]. 2016 [Citado 2017 feb 25]. Disponible en: http://www.who.int/malaria/areas/vector_control/DraftWHO-GVCR-2017-2030.pdf?ua=1\&ua=1

5. World Health Organization. Mosquito (vector) control emergency response and preparedness for Zika virus [internet]. Geneva; 2016. [Citado 2017 feb 25]. Disponible en: http:// www.who.int/neglected_diseases/news/mosquito_vector_control_response/en/

6. Pieper J. Virtudes fundamentales. Madrid: Rialp; 2010.

7. Gene editing, clones and the science of making babies. The Economist [internet]. 2017 feb 18. [Citado 2017 feb 28]. Disponible en: http://www.economist.com/news/leaders/21717035ways-reproducing-without-sexual-intercourse-are-multiplying-history-suggests-they-should

8. Harmon A. Human gene editing receives science panel's supports. The New York Times [internet]. 2017 feb 14 [Citado 2017 feb 28]. Disponible en: https://www.nytimes. com/2017/02/14/health/human-gene-editing-panel.html?_r=0 
9. Center for Genetics and Society. Human gene editing: A timeline of CRISPR cover stories [internet]. [Citado $2017 \mathrm{feb}$ 28]. Disponible en: http://www.geneticsandsociety.org/article. php?id=9618

10. Lamprea-Bermúdez N, Lizarazo-Cortés O. Técnica de edición de genes Crispr/Cas9: retos jurídicos para su regulación y uso en Colombia. Rev Prop Inmaterial. 2016;21(1):79-110. doi: 10.18601/16571959.n21.04

11. Doudna JA, Charpentier E, Jinek M, et al. A programmable dual-RNA-guided DNA endonuclease in adaptive bacterial immunity. Science. 2012;337(6096):816-21. doi: 10.1126/ science. 1225829

12. Battle billions: scientists go war over lucrative gene editing patents. South China Morning Post [internet]. 2017 feb 24. [Citado 2017 feb 24]. Disponible en: http://www.scmp.com/ news/world/article/2073737/battle-billions-scientists-go-warover-lucrative-gene-editing-patents

13. Colgrove J. Investing in people: The Greenwall Foundation's bioethics programs. A Report to The Greenwall Foundation [internet]. May 2012. [Citado 2017 mar 3]. Disponible en: http://www.greenwall.org/pagedocs/Greenwall_Bioethics_ History.pdf
14. President's essay. Annual Report 2014 [internet]. [Citado 2017 mar 3]. Disponible en: https://www.macfound.org/ annual-report/2014/essay/?page $=4$

15. Annual Report and Financial Statements 2016 [internet]. [Citado 2017 mar 3]. Disponible en: https://wellcome.ac.uk/ sites/default/files/WellcomeTrustAnnualReportFinancialStatements_160930.pdf

16. CRISPR/Cas9 used for rapid functional study of cancer-causing genes [internet]. [Citado 2017 mar 3]. Disponible en: http://www.sanger.ac.uk/news/view/crisprcas9-used-rapidfunctional-study-cancer-causing-genes

17. Directorio de organizaciones [internet]. [Citado $2017 \mathrm{Mar}$ 3]. Disponible en: https://www.nodoka.co/es/3/w-k-kelloggfoundation

18. Gage A. Sexual activity and contraceptive use: the components of the decision making process. En: Arias L, Ceballos J. No solo el amor te salva. Cali: Universidad del Valle. Fundación W. K. Kellogg-Feriva; 2003. p. 98.

19. Jóvenes Latinoamerican@s Unid@s en Respuesta al VIH y SIDA (JLU) - Latin American Youth United In Response to HIV and AIDS. [Citado 2017 mar 3]. Disponible en:http://comminit.com/citurnatv/category/partners/wk-kellogg-foundation 